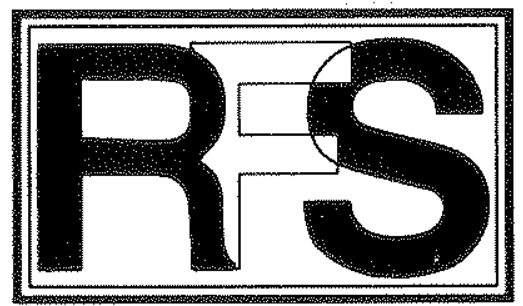

Revista de Fomento Sociut, 49 (1994), 285.316

1

\title{
EI SOC: \\ Un caso de reacción campesina ante la modernización rural ${ }^{1}$
}

En primer lugar, en este trabajo, se destina un extenso apartado a realizar una sintesis aproximativa a la evolución del problema de la reivindicación de la reforma agraria y de la tradicional conflictividad en el agro andaluz. Sobre todo, la finalidad de tal apartado es mostrar los origenes y la trayectoria seguida por el proceso socio-histórico de modernización del agro (paralela a

(1)Texto modificado de la ponencia presentada al IV Congreso Español de Sociología, celebrado en Madrid en septiembre de 1992, con el lítulo "El Sindicato de obreros del Campo (SOC): un paradigma de organización y de movilización campesina en una sociedad rural en crisis de modernización". Agradezco a J. J. Romero, miembro del Consejo de Redacción de la RFS, las sugerencias que ha efectuado a mi trabajo originario, las que sin duda han contribuido notablemente a la mejora del mismo. En cualquier caso, de los errores y carencias que pueda presentar este artículo soy yo el único responsable.

(*) Profesor Titular de Sociologia de la Universidad de Granada.

\section{ESTUDIOS}


La de la sociedad española en su conjunto) que dio lugar al contexto en el que se situa el surgimiento y evolucion del Sindicato de obreros del Campo (SOC). Posteriomente a ello, tras dedicar un eplgrafe a contextualizar el caso del surgimiento de este sindicato en el marco de la restauración democrática y del aftanzamiento de las otras organizaciones de asalariados agricolas españolas, se efectúa un estudio de los contenidos del periódico del SOC "Tierra y Libertad" (TYL) y de otros documentos relacionados con esta organización relvindicativa, correspondientes, en su mayoría, al período comprendido entre los ulltimos años de la década de los setenta y los primeros ochenta. A partir de este análisis de contenidos, se tratan de determinar algunas de las características más sobresalientes de dicho Sindicato. Finalmente, en la conclusión, se reflexiona acerca de las motivaciones del rechazo del SOC a la modernización y en torno a la necesidad de aplicar soluciones al mundo rural teniendo en cuenta la inserción de este en la dinámica económica global, asi como acerca de la viabilidad de las alternativas utopico-radicales en las complejas y altamente integradas sociedades actuales.

\section{Introducción}

Durante los últimos años de la década de los setenta y los primeros de la de los ochenta (período de tiempo en el que se centra este estudio) las dificultades económicas contribuyeron a producir una paulatina disminución de las posibilidades de emigrar de la poblacion laboral rural hacia otros sectores de actividad económica. Asimismo, a fin de adecuar las estructuras productivas de nuestro país de cara a su ingreso en la C.E.E., se prosiguió incentivando el proceso de progresiva reducción de mano de obra y de modemización en la agricultura que se había iniciado con especial intensidad, sobre todo, a partir de la década de los años cincuenta. Este es el marco de surgimiento del Sindicato de Obreros del Campo (SOC) y de mayor efervescencia de las movilizaciones del mismo. Organización sindical y/o movimiento social que entronca con la tradicional dinámica de movilizaciones existente en el agro andaluz y que, además, puede ser conceptuado como una forma de reacción campesina frente a los efectos desarticuladores que para su mundo conlleva el presente proceso de modemi-

\section{RFS}


zacion. Proceso este, cuyos primeros efectos ya se hicieron notar en el siglo XIX; precisamente, uno de los períodos de mayor conflictividad social en el campo andaluz.

El mero análisis de los documentos del SOC, en el que se basa el presente escrito, puede dar al lector la sensáción de que el ideario de éste constituye una especie de totalidad integrada, lo que no concuerda exactamente con la realidad heterogénea y relativamente fragmentada de dicha organización. Lejos de ser una entidad monolítica, el SOC, como cualquier otra organización, alberga en su senodistintas corrientes y/o actitudes estratégicas que van desde el reformismo y la relativa moderación que, por referir un ejemplo, caracteriza al ecologismo propugnado por el dirigente Paco Casero, a las posturas más radicales de, por citar otro caso, líderes como Diego Cañamero o Juan Manuel Sánchez Gordillo. De todas formas, las diferencias intemas (que no han implicado, usualmente, la existencia de acusadas divisiones y/o divergencias) son más manifiestas en el SOC que en otros sindicatos; precisamente, por el arraigado rechazo a toda forma de organización político-burocrática presente en el mismo que, en consecuencia, manifiesta un escaso nivel de vertebracion desde el punto de vista institucional. Además, tales diferencias se han ido haciendo más patentes a medida que, con el transcurrir de los años, ha ido evolucionando el SOC que, más que una organización sindical plenamente integrada, puede ser considerado como una especie de movimiento social coyuntural; es decir, surgido como una aglutinación de fuerzas sociales, relativamente heterogénea, en el contexto de la crisis que, por efecto de la modernización, atravesaba el agro andaluz en la época de su aparición. Un movimiento, asimismo, con una naturaleza asamblearia y con un apreciable nivel de fragmentación de tendencias.

La perspectiva sociológica tipificada como etnometodologia ha puesto de manifiesto que suele existiruna discordancia, más o menos pronunciada según los casos, entre los procesos interactivos intemos y las conversaciones que tienen lugar en el seno de una organización cualquiera, de una parte y, de otra, la codificación final, en la que realmente consisten los informes u otros documentos destinados a presentar la que puede considerarse como imagen o versión "oficial" de la organización (Entrena: 1992 (a), 272). Aunque en el SOC, dado su escaso grado de burocratización, la discordancia entre lo "real" y lo "oficial" es mínima, lo cierto es que tal discordancia también existe. Por ello, para comprender cabalmente tal organización sindical sería preciso

\section{ESTUDIOS}


analizar los procesos intemos que han marcado su genesis y evolucion sociohistorica.

No obstante ello, aquí se van a pasar por alto tales diferencias y sectores, pues se considera que, a pesar de sus limitaciones, la estrategia analítica de confinarse al estudio de los contenidos de los que pueden considerarse como documentos "oficiales" del Sindicato resulta, como se tratará de mostrar en este trabajo, muy adecuada para aproximarse a la comprension de la ideología, marcos conceptuales y simbólicos, en tomo a los que se ha legitimado la acción socio-política del SOC.

Lejos de ajustarse a los procedimientos formalizados, preestablecidos ya para este fin, el análisis de contenidos que se ha efectuado para llegar a estas conclusiones se basa, sobre todo, en una interpretación libre de textos, que no se adecua, ni lo pretende, a los criterios predefinidos para ello. Un paso en el análisis ha sido dejarque los textos hablen por si solos, entrar en su propia logica discursiva y tratar de comprenderla y de captar su intencionalidad. También, se ha procedido a la conceptualización de dicha lógica, de acuerdo con la teoria sociológica y con los enfoques interpretativos existentes con referencia a los movimientos sociales campesinos. La finalidad de todo ello es poner de manifiesto las motivaciones, y la percepción de la realidad socio-económica en la que se hayan inmersos, que tienen los campesinos del SOC.

1. Sobre la reivindicación de la reforma agraria y la tradicional conflictividad campesina en el agro andaluz

Las luchas campesinas en demanda de una distribución más equitativa de la propiedad de la tierra han existido, en España, desde hace varios siglos y han estado ocasionadas por diversas motivaciones. Ya durante los siglos XVI y XVII se tiene conocimiento de la existencia de movimientos de protesta originados por la venta de baldíos. También, se sabe de la generación de revueltas populares a raíz de las sentencias dictadas a favor de la nobleza con ocasión de los pleitos de señorío. Análogamente, algunas de las ventas de tierras, efectuadas al amparo de la desamortización, dieron lugar al estallido de revueltas.

Secularmente los movimientos campesinos andaluces han estado motivados, sobre todo, por las fuertes desigualdades que han existido en la estructura de distribución de la propiedad de la tierra. Hay que tener en cuenta que la tierra 
representa un factor económico-productivo y simbólico primordial en el marco de la sociedad campesina tradicional. En este contexto, el control y/o la propiedad de la tierra constituye, por consiguiente, una de las principales bases de sustentación, de mantenimiento y de reproducción de la estratificación social y, por lo tanto, de la estructura de clases. Es partiendo de la modalidad de tenencia o de propiedad de la tierra, así como de las relaciones de producción que se han desarrollado en el espacio rural (Entrena: 1992(b)), como se puede proceder a delimitar los criterios, con respecto a los cuales se configura la estratificación social en el medio agrario. Tales criterios pueden esquematizarse del modo que sigue:

19) La cantidad y la calidad de las tierras que se poseen es un indicador social fundamental para deteminar la posición económica y el status sociopolítico de sus dueños.

$2^{\circ}$ ) La propiedad y la ascendencia de los propietarios constituyen factores básicos para determinar el prestigio que aquellos poseen a nivel local y el poder que ejercen, o pueden ejercer, fuera de este ámbito; por ejemplo, en la política a escala nacional.

39) La circunstancia de poseer la tierra o de ser hijo de un propietario resulta decisiva para tener, prácticamente, garantizada la posibilidad de acceder a los puestos básicos de control y/o de decisión política (Sánchez Jiménez: 1985, 17).

Así pues, dado que la posesion de la tierra es, en el medio rural tradicional, un recurso básico para deteminar la posición ocupada por los sujetos en la estructura social, a la vez que para decidir la función que se desempeñara en el marco global de la sociedad, resulta comprensible que, en dicho medio, la conflictividad campesina haya estado, con bastante asiduidad, vinculada a las disputas por la propiedad y/o el control de ese recurso econónico fundamental. En este contexto, la petición de la reforma agraria, entendida habitualmente como reivindicación de un reparto más igualitario de la tierra, ha constituido una de las aspiraciones más reiteradas y corrientes de aquellas por las que se han levantado las masas de desposeídos de la sociedad rural.

Aparte de las grandes concentraciones latifundistas, que sobre todo han predominado en Andalucia occidental, hay otros problemas que es preciso 
considerar para comprender como ha podido originarse la conciencia social de la necesidad de aspirar a una reforma agraria (Perez Yruela: 1985, 4 y ss.), cuya reivindicación colectiva ha constituido, historicamente, la principal fuente de legitimación de los movimientos sociales campesinos andaluces. En primer lugar, hay que tener presente que las areas de grandes concentraciones de propiedad del suelo agrícola han sido también, tradicionalmente, las zonas de existencia de un gran número de jomaleros o braceros que, en consecuencia, se veian impelidos a experimentar cotidianamente la imposibilidad de acceder a la propiedad de una parcela. Por otra parte, de no haberse unido al hecho, de por sí conflictivo, del fenómeno latifundista la circunstancia de que éste se diera en zonas de fuerte concentración dernográfica, es muy probable que no se habría producido esa situación, en la que la cuestión de la desigual distribución de la tierra se erigió en un problema de primera magnitud.

La conflictividad está relacionada, también, con el grado de legitimidad que la mayoría de campesinos desposeídos confieren a la desigualitaria estructura de distribución de la propiedad territorial en la que se hallan inmersos. Tanto los meros jomaleros como los pequeños propietarios campesinos, que son los sectores que siempre han estado más propensos a reivindicar la reforma agraria, han manifestado muchas veces sus dudas en tomo a la moralidad y justificación social del fenomeno latifundista. Asimismo, han expresado repetidamente sus críticas a la que consideraban que era una deficiente forma de explotar las grandes propiedades agrícolas, así como al mal aprovechamiento de los recursos naturales y a la frecuente despreocupación y absentismo, por parte de los propietarios, con respecto a sus fincas. Los jornaleros, y muchos otros preocupados por los problemas del mundo rural, han pretendido encontrar en el latifundio el origen de los grandes males que aquejaban a la sociedad campesina andaluza: desempleo estacional crónico, bajos salarios, analfabetismo, pobreza, subdesarrollo, etc., etc. (Carrión: 1932).

Es cierto que muchos de los problemas que se acaban de mencionar se pueden explicar a raíz de la existencia de latifundios y de la desigualitaria estructura social que estos generan, así como por el inadecuado modo con que, por lo general, han sido explotadas las grandes fincas. La tendencia a adoptar el monocultivo, por parte de éstas, conlleva, inevitablemente, el desempleo estacional, a la vez que, en unas condiciones de un relativamente bajo nivel de desarrollo tecnológico y de modemización del agro, su orientación extensiva de

\section{RFS}


la producción da lugar a la creación de menos cantidad de empleo que la intensiva. Asimismo, la concentracion de la propiedad, en detrimento de las grandes masas de jomaleros sin tierra, propicia que éstos desarrollen una percepción de estar siendo explotados. Todo ello, en consonancia con su experiencia real de encontrarse envueltos en unas relaciones socio-económicas de dependencia con respecto a los propietarios. Circunstancias estas que contribuyen a agudizar los sentimientos de enajenación y de privación relativa de los menos favorecidos. Además, es cierto que la gran propiedad suele conllevar, con asiduidad, un cierto nivel de despilfarro de los recursos y una menor preocupación por obtener provecho de todo aquello que sea susceptible de reportar utilidad económica. Se trata de una mentalidad bastante ajena a cualquier pretensión de lo que se podría tipificar como esa tendencia a maximizar los rendimientos productivos característica de una cultura empresarial moderna. Esta situación choca con la mentalidad de los pobres, los que, dado que se ven obligados a aprovechar los escasos recursos de que disponen hasta el límite, difícilmente pueden comprender y tolerar la existencia de recursos ociosos, por muy escasos que éstos puedan ser.

Sin embargo, aparte de lo dicho, es asimismo verdad que la persistente conflictividad campesina andaluza derivaba, además, de otras causas, tales como el bajo nivel de desarrollo que existía en otros sectores económicoproductivos, los que, en consecuencia, no estaban capacitados para absorber los excedentes de mano de obra provenientes del medio agrario. También, las reiteradas fluctuaciones $y / o$ caídas de los precios de los productus agrarios, con sus subsiguientes efectos sobre la disminución de los salarios, así como las malas cosechas ocasionadas por las sequías o por otros contratiempos climatológicos, son causas posibles del malestar social y de las revueltas que ello ocasionaba con tanta frecuencia.

- La situación se hizo especialmente problemática durante el último tercio del siglo XIX. Fue entonces cuando tuvo lugar la culminación de las medidas desamortizadoras y del proceso de aplicación de la serie de disposiciones legales, tendentes a propiciar el definitivo desmantelamiento del sistema de vinculaciones patrimoniales característico del Antiguo Régimen. Ello conllevó la decisiva instauración de la propiedad privada de tipo liberal-capitalista en el medio agrario. Propiedad que tendió a concentrarse cada vez más, al mismo tiempo que se agudizaba el proceso de desaparicion y de fragmentación de las

\section{ESTUDIOS}


pequeñas explotaciones. Se consolido, de este modo, un sistema latifundista sin modemización o de modemización limitada en la Baja Andalucía, frente a otro sistema de colonato, de caracter semiproletario y sometido a la gran propiedad, en la Alta (Barragán, González y Sevilla: 1985, 23).

Tal sistema, que contó con unos precios garantizados para los productos agrícolas - sobre todo, los cereales - y con una abundante y barata mano de obra, hacía que se tornara innecesaria cualquier alternativa de mecanización, ya que la liberalización absoluta del mercado de trabajo, propiciada por las medidas legislativas del Estado de la Restauración, permitía la contratación estacional, la cooptación de los jornaleros y el mantenimiento de los salarios a la baja.

Se explica así que, para los campesinos sin tierra (de cuyo tradicional uso desde siglos habían sidodesposeídos porefectode las medidas desamortizadoras) y condenados a percibir un escaso y estacional jomal, resultara normalmente intolerable el contraste existente entre la riqueza, por lo usual ostentosa y opulenta, de las clases terratenientes y sus míseras condiciones de vida. En este contexto, la reforma agraria, denominada como 'reparto' por la población campesina, pasaría de modo sistemático a formar parte de las reivindicaciones de los desposeídos del agro. En sucesivas etapas de conflictividad social los campesinos plantearon la demanda del 'repano' en conjunción con otras, tales como el aumento de los salarios, la eliminación del trabajo a destajo, o la necesidad de poner límites a la contratacion de forasteros que, con frecuencia, eran utilizados por los propietarios agrícolas como mano de obra altemativa ante la huelga de los locales.

En el por ellos mitificado 'reparto' los campesinos proyectaban, habitualmente, sus ancestrales ansias de solucion de los problemas que, desde hacía siglos, los acuciaban. El 'reparto' era considerado por ellos como una aspiración má-xima, no siempre bien concretada, y que, en reiteradas ocasiones, generaba en sus mentes unas expectativas y unas actitudes colectivas tan altas y entusiastas como correspondía a la "vida nueva" que ellos creían que, inevitablemente, sobrevendría a raíz del mismo. En cierto modo, el 'reparto' de tierra era entendido como una especie de nueva y más igualitaria desamortización mediante la que lograr la realización del ideal de dicha general añorado por aquellos campesinos:

" ¿No se trataba de conseguir la felicidad de todos y que todos fueran iguales? ¿No era la posesión de la tierra el medio de que disponían los 
burgueses para disfrutary serdichosos? Pues, evidentemente, los trabajadores también lo serian cuando dispusieran de su suerte de ticra como disponían de su azada. ¡La cantidad de tierra monopolizada era enome! ¡Habia para todos, hasta para los burgueses! Esta creencia en el reparto se hizo general en las masas" (Díaz del Moral: 1979, 199).

Tan utópicas expectativas y actitudes colectivas solían, pues, carecer de un conocimiento adecuado de las posibilidades que para ello ofrecía la realidad sobre la que se desarrollaban. En consecuencia, no disponian, habitualmente, de planes racionalmente estructurados y organizados para ser tlevadas a su materialización práctica. El apoliticismo usual de las masas campesinas, identificadas en gran parte con el paradigma organizativo anarquista, tuvo mucho que ver en esta ausencia de planes racionalmente instrumentalizados para llevar a cabo sus aspiraciones. El anarquismo suele ser un fenómeno bastante generalizado entre los campesinos del mundo tradicional. Para ellos:

"...el Estado es algo negativo, un mal, que debe reemplazarse lo más pronto posible por su propio orden social de 'carácter doméstico'. Ese orden, creen, puede existir sin un Estado; por lo tanto, los campesinos rebeldes son anarquistas naturales" (E.R. Wolf: 1979, 400).

Aparte de ello, habria que preguntarse acerca de las causas concretas del enorme arraigo popular de la forma de organización anarquista en la sociedad agraria de la España decimonónica. José Alvarez Junco (1976, 588-599) sugiere los tres tipos de explicación siguientes: la económico-social, la religiosa y la político-institucional. En primer lugar, el irregular desarrollo económico-social del país conllevó la coexistencia de formas organizativas e ideologías capitalistas avanzadas con supervivencias casi feudales, artesanales y agrícolas, con predominio de las segundas sobre las primeras. Concrelamente, en Andalucía, el anarquismo desempeñó un fuerte influjo en estos medios, ya que conect 6 bien con los valores, las simbologías y las inquietudes peculiares de la existencia del campesinado tradicional, del que tomo sus ancestrales reivindicaciones y al que supo hablar en su propio lenguaje, consagrando sus típicas formas de insurrección organizada más o menos espontáneamente. Por otra parte, en el rápido y casi repentino proceso de secularización experimentado por la sociedad espa- 
ñola durante el siglo XIX, el anarquismo vino a cumplir para las clases trabajadoras una función equivalente a la que antes había desempeñado la Iglesia (defensora de principios ético-sociales como la igualdad humana esencial, las formas comunitarias y la solidaridad entre los más humildes de la escala social). Finalmente, en el nivel político-instiucional, es manifiesta la decepción de los campesinos ante la Administración española decimonónica caracterizada por la corrupción, la imprevisibilidad de los reiterados golpes de Estado y los pronunciamientos militares, así como por la ineficacia en lo relativo a resolver las preocupaciones cotidianas más inmediatas de la población. Se explica, así, el apoliticismo (cuando no antipoliticismo) característico del anarquismo hispano en este período. También, el extremado antipoliticismo del pueblo campesino decimonónico puede ser entendido, sobre todo, como la expresión de un rechazo visceral a todo aquello que representa al Estado artífice de esa serie de medidas sociopolíticas y legales, encaminadas a desmantelar el Antiguo Régimen que, en la práctica, conllevan radicales alteraciones y la casi completa desarticulación de modo de vida de la sociedad campesino-tradicional. Medidas todas ellas tendentes a crear el marco normativo-junídico, sobre el que, posteriormente, fue posible llevar a cabo el proceso de industrializacion modemizadora de la sociedad hispana que, como ha solido ser habitual en la generalidad de los casos, se hizo desde arriba y sin contar con los intereses populares. Hay que tener en cuenta, con referencia a esta cuestión, que:

"...no hay indicio alguno de que el pueblo de ningún país haya quetido una sociedad industrial, y multitud de indicios de lo contrario. En el fondo, todas las formas de industrialización han sido hasta aquí revoluciones desde arriba, la obra de una minoría despiadada" (B. Moore: 1991, 408).

Todo lo que se acaba de decir contribuía a que la conflictividad social se expresase mediante formas de comportamiento, en las que se manifestaba un alto grado de fervor colectivo, propiciado y legitimado en el marco racionalista y relativamente secularizado de los ideales anarquistas, y que generaba situaciones más próximas al profetismo y al milenarismo utópico que a cualquier forma de protesta institucionalizada y estructurada mediante estrategias, marcos conceptuales-simbólicos y aspiraciones susceptibles de ser formuladas de 
acuerdo con lo que, en téminos de Max Weber, podría ser tipificado como una racionalidad instrumental medios-fines, claramente definida.

- La idea de que la desigualdad socio-económica de la sociedad rural del sur representaba una fuente de conflictividad social de consecuencias imprevisibles, y de que, por lo tanto, había que esforzarse en encontrar alguna forma de atajar o resolver este problema, comenzo a arraigar paulatinamente en la conciencia de los gobemantes. Es de este modo como se comprende la creación de organismos como el Instituto de Reformas Sociales, en 1903, que ese mismo año convocó un concurso, bajo el patrocinio del Rey, en tomo al "problema agrario del sur". Sin embargo, los distintos proyectos y medidas legislativas encaminados a resolver la cuestión social andaluza no prosperaron por distintas razones. Luego, la II República, que en principio abrio grandes esperanzas para los campesinos, tampoco logró resolver el problema de las desigualdades en la distribución de la propiedad agraria. Entre las razones de este fracaso, Martínez Alier señala que los políticos de la República (incluyendo la coalición Azanasocialistas del primer bienio) no "se lanzaron a este empeño con el entusiasmo de que hubieran hecho gala si los latifundios hubieran sido todavía, en el siglo XX, propiedad de la iglesia o de los aristócratas $(1978,230)$.

También contribuyeron a dicho fracaso la lentitud de aplicación de las medidas de reforma agraria, la irritación de los campesinos que como consecuencia de ello se produjo, y la paralización a que se vio sometida la reforma durante el bienio conservador. Todo ello repercutió en la radicalización de las posiciones políticas y en que los conflictos sociales acabaran por desestabilizar el régimen republicano, que tantas esperanzas había despertado entre los trabajadores en su comienzo (Pérez Yrucla: 1985, 17).

El franquismo no solventó las desigualdades estructurales existentes tradicionalmente en el medio rural. De hecho, el franquismo, ya durante la contienda civil de 1936-39, procedio a devolver las tierras a aquellos no numerosos propietarios que habían sido afectados por las medidas de reforma agraria llevadas a cabo durante la II República. Sin embargo, durante el franquismo se produjo también (especialmente, a partir de los años cincuenta) un proceso de industrialización general, así como de mecanización y de modernización del sector agrario, que implico el trasvase de una gran proporción de mano de obra de éste a los sectores industrial y de servicios. Esto conllevó un masivo éxodo de población rural a los centros urbanos que, unido 
a la gran proporcion de emigrados al extranjero, supuso un relativo alivio para la situación de los trabajadores que se quedaron en el campo, en lo relativo a la elevación del nivel de sus salarios y a una considerable mejora de sus condiciones de vida y posibilidades de encontrar trabajo; aunque, de todas formas, se mantuvo una apreciable proporción de desempleo.

No obstante, lo cierto es que la modernización general, y específicamente en el ámbito agrario, propiciada porel franquismo no se planteo nunca, ni tampoco tuvo como efecto una modificacion de las condiciones estructurales que propiciaban la desigualdad en el medio rural. Lo que realmente se hizo consistió, sobre todo, en una reforma agrícola que se preocupo, fundamentalmente, por inducir a los propietarios de tierras a incrementar la productividad a través de la mecanización y tecnificación de sus explotaciones.

2. La restauración democrática y el afianzamiento del sindicalismo libre. El caso del SOC

Al finalizar la dictadura franquista dejó de tener vigencia el discurso de la pretendida armonía de los intereses agrarios encarnado por las Hermandades de Labradores y Ganaderos. Al amparo de la ley de libertad sindical promulgada el 1 de abril de 1977, se pasó del corporatismo característico del sindicato vertical, en el que por obligación estaban afiliados todos los trabajadores y/o empresarios agrícolas, a la emergencia, en el nuevo marco sociopolítico pluralista, de una diversidad de asociaciones voluntarias en consonancia con la heterogeneidad socio-económica y regional de nuestro medio agrario (Moyano: 1984).

A partir de 1976, al amparo de la libertad recobrada como consecuencia de la restauración democrática, se alentó entre diversos sectores sociales e intelectuales españoles la idea de que de nuevo se presentaba un marco socio-político adecuado para plantear las viejas reivindicaciones sociales. En esta situación se produjo un recrudecimiento de las luchas sociales en el campo andaluz que mostraba la persistencia del paro estacional, así como de unos problemas y de unas tensiones sociales menos graves, evidentemente, que en anteriores épocas, pero no por ello superados. Persistían, según Martínez Alier, las tradicionales ideas e ilusiones de la aspiración al 'reparto' (sin que ello implicara la fragmentación en lotes de los 'cortijos" $)(1978,235)$. Coincide en este punto con 
Martínez Alier, J.J. González, quien se ha expresado en los términos del texto que a continuación se transcribe:

"Quedaban así bien sentados los siguientes supuestos: primero, la tradicional aspiración al 'reparto' seguía arraigada en la conciencia jomalera, pese a las transfomaciones sociales ocurridas tanto en la industria como en el campo tras la guerra civil (coyuntura trágicamente frustrada para el cumplimiento histórico del 'reparto').

Segundo, tal aspiración lejos de ser espontánea, estaba apoyada en una - crítica central al latifundismo, en cuanto estructura social agraria, y a los patronos en su triple condición de propietarios ilegítimos, de empresarios incompetentes (en cuanto a su estrategia de cultivo) y de sujetos superfluos en el proceso de producción" $(1989,41)$.

Este es el contexto de afianzamiento de las asociaciones sindicales libres espaniolas de asalariados agrícolas. Con referencia a ellas, hay que mencionar a la Federacion de Trabajadores de la Tierra (FTT), a las Comisiones Obreras del Campo (CCOO) y al Sindicato de Obreros del Campo (SOC). Mientras que la FTT y las CCOO son sindicatos de implantación a nivel estatal que están integrados en el seno de organizaciones sindicales obreras de carácter general como son, respectivamente, la Unión General de Trabajadores (UGT) y las CCOO, el SOC es una organización reivindicativa exclusivamente dedicada a los asalariados agrícolas y, además, su implantación se circunscribe, básicamente, a una parte del territorio de las provincias occidentales andaluzas de Sevilla y Cádiz.

Los encierros en la Diputacion de Sevilla o en la sede de otras instituciones públicas, las marchas de jomaleros a Sevilla incluso a Madrid, las ocupaciones simbolicas de fincas que a juicio del sindicato estaban mal explotadas, las huelgas de hambre, la exigencia a los patronos de que se repartieran los trabajadores y los emplearan en sus cortijos o, por ultimo, las paradas de las máquinas cosechadoras constituyen algunas de las acciones reivindicativas más comunes y que más eco han tenido en la opinion pública de las llevadas a cabo por el SOC .

(2) Por ejemplo, puede encontrar el lector referencias con respecto a ello en el periódico 
La gran resonancia pública de sus acciones, así como la fuerte determinación con que han sido planteadas sus exigencias y el tono de sus discursos, le han valido al SOC el calificativo de radical. Si bien dicho calificativo responde a la realidad de los hechos, de ello no ha de desprenderse la errónea apreciación de que esta organización ha actuado siempre orientada por un rechazo frontal del sistema incapaz de cualquier conciliación o acuerdo. De hecho, la opción por el pacto y la actitud favorable a la firma de convenios, que ha estado siempre presente en el sindicato ${ }^{3}$, parece haberse ido acentuando a medida que ha ido transcurriendo el tiempo, de tal forma que esta organización muestra un proceso de creciente inserción en las pautas de la cultura política de la negociación.

Con relativa frecuencia se produjo una convergencia de actuación entre el SOC y las CCOO. La mayor radicalidad de los planteamientos de las CCOO del campo de los primeros años de la restauración democrática, junto con el fuerte arraigo que tuvo este sindicato en la clandestinidad en Andalucfa occidental (es decir, la zona de influencia del SOC) ${ }^{4}$, son hechos que contribuyen a explicar las confluencias, a la hora de plantear movilizaciones y estrategias reivindicativas comunes, de estas dos organizaciones en el período aquí analizado.

Por otra parte, tanto la FTT como las CCOO del campo suelen tender a considerar la situacion de los jomaleros como globalmente vinculada y/o

Tierra y Libertad (TYL) núms. siguientes: marzo 1982, pág. 3; septiembre 1982, págs. 5 y 8 ; y, febrero 1983, pág. 3 .

(3) Aś, en las páginas de TYL aparecen distintas referencias alusivas a la firma (o a la necesidad de firmar aquellos que por algún motivo permanecen estancados) de convenios con la patronal, así como relativas a conversaciones con la administración. Tal es el caso de los núms, siguientes: diciembre 1982 , pág. 4 ; julio-agosto 1982, pág. 4; enero 1983 , pág. 3 ; febrero 1983, pág. 4; y, abril 1983, págs, 4-5.

(4) Las que primero fueron denominadas comisiones jornaleras, surgieron en la clandestinidad a mediados de la década de los sesenta, cuando se inició el proceso de rearticulación general del movimiento obrero español. Las condiciones salariales en la comarca de Jerez, los primeros convenios y conciertos en la recogida del algodón y de la aceituna, las huelgas etc, constituyeron algunas de las acciones de carácter reivindicativo más destacadas de las llevadas a cabo en Andalucía occidental por aquellos años, en los que el sindicato CCOO fue organizado mediante la infiltración de sus cuadros en la estructura del sindicalismo oficial franquista (MORALES y BERNAL: $1993,257-258$ ).

(5) Respecto a esta cuestión existen diversos documentos. Como muestra de ellos pue den consultarse los números siguientes de TYL: septiembre 1982, pág. 5; y, diciembre 1982 , págs. 4 y 5 . 
relacionada con la del resto de los trabajadores de otros sectores productivos, tales como la industria o los servicios. Ello es posible, entre otras razones, porque estas organizaciones de asalariados agrícolas están integradas en el entramado organizativo general de las confederaciones sindicales a las que, respectivamente, corresponden; es decir, la UGT y las CCOO. Confederaciones estas, dentro de las cuales el predominio intraorganizalivo está, por lo habitual, en manos de los obreros no agrícolas. En cambio, el SOC, al ser un sindicato cuya actuación se ha centrado especialmente en el medio agrario, se ha preocupado, sobre todo, de la situación específica de los jornaleros. Ello no quiere decir que el SOC no haya tratado de enfocar este estado de cosas también desde una perspectiva totalizante, tendente a ubicar dicha situación en el marco global de los efectos desarticuladores que la modernización acarrea sobre el mundo agrario.

A diferencia de la FTT y de las CCOO del campo que, en líneas generates aceptaron la Ley de Reforma agraria del gobiemo andaluz, a la que sólo plantearon críticas puntuales (hay que precisar que más radicales por parte de las $\mathrm{CCOO}$ ), en lo que se refiere al SOC, su estrategia reivindicativa se centro en el período analizado en este trabajo, sobre todo, en la reivindicación de un tipo de reforma agraria distinto al propuesto por el gobiemo de Andalucía, considerada a su juicio como insuficiente y no adecuada a las necesidades de los campesinos. Este rechazo a la altemativa gubemamental de reforma agraria se debe a que el SOC estima que ésta contribuirá a agudizar los efectos desarticuladores de la modernización sobre el mundo rural, lo que, a su entender, conllevará más paro y, en definitiva, la pérdida de la condición de trabajadores relacionados con la tierra que el sindicato reivindica para los jomaleros.

"Pero he aqui que los hombres y mujeres del campo que venimos siendo abofeteados por el paro no vamos a consentir más atropellos ni más humillaciones. Entérense, pues, y de una vez, señores del Gobierno, de que lo que queremos es trabajo y trabajo en la tierra o alrededor de la tierra" (TYL: 1982 julio-agosto, editorial).

Dicho en sus propios téminos, se trata de una ley de reforma agraria que no es buena porque: 
"...no toca la injusta estructura de la propiedad de la tierra. Porque es una 'reconversion' del campo que lleva consigo la eliminación de trabajo. Porque no da altemativa a los trabajadores y nos arroja al paro y al desempleo. Porque va dirigida a dar más riqueza a los ricos. Porque es una pura 'modernización' capitalista del campo. Porque supone una operación política engañosa para robar a los jomaleros una bandera de lucha. Porque está suponiendo engaño, confusión y frustración en los trabajadores y enfriamiento en las luchas. Porque no rompe con la dependencia de Andalucía, sino que nos va a hipotecar más aún al Capitalismo de las multinacionales. Porque no contempla el desarrollo de otros sectores de la economía andaluza" (Cuarto Congreso: 1987, 12-13).

Críticas similares a la Ley de reforma agraria de la Junta de Andalucía, así como propuestas acordes con la concepción que el SOC tiene de la misma y muestras de las expectativas que ella despierta, aparecen en diversos números de TYL ${ }^{6}$. En la generalidad de los escritos del SOC se manifiestan una serie de características que constituyen el objeto de análisis del siguiente epígrafe.

\section{Algunas de las características del SOC extraídas a partir del análisis de los contenidos de sus textos}

Una de las reivindicaciones básicas explícitas de esta organización ha sido la reforma agraria. Una cuestión a considerar, que excede los propósitos de este trabajo, es la de la conveniencia y oportunidad de llevar a cabo una reforma agraria en la Andalucía actual, así como la manera en que, en caso de haberse efectuado dicha reforma, ésta debería haber sido concebida. El hecho de que la propiedad de la tierra por sí misma haya dejado de ser un factor determinante de la posición que se ocupa en la estructura socio-económica del agro, los obstáculos que han supuesto para la modemización de éste determinados procesos de reforma agraria consistentes en la mera parcelacion de la tierra entre los campesinos, así como la mayor capacidad del término desarrollo del medio rural (siempre que éste sea planteado adecuadamente y desde una perspectiva

(6) Véase, por ejemplo, el editorial de los números 10-11 de TYL, correspondientes a los meses de julio y agosto de 1982 . 
global) para explicar y afrontar la generalidad de problemas que hoy se te presentan a dicho medio, son, entre otras diversas, algunas de las razones que han incidido en que, poco a poco, se vaya experimentando una tendencia a utilizar tal término para designar unas nuevas estrategias de acción sociopolítica sobre el agro tendentes a reemplazar con sus funciones a los papeles otrora atribuidos a la reforma agraria.

La mera propiedad de la tierra ya no constituye por sí sola un factor decisivo, como lo fuera en la sociedad rural tradicional, para determinar la posición que se tiene en la estructura social, sobre todo, debido al elevado nivel de division soclal del trabajo y a la compleja estructura ocupacional de las sociedades modernas actuales. Además, ¿de que serviría un reparto de la tierra si los campesinos no controlan el proceso de comercializacion de sus productos, si carecen de mentalidad empresarial, de recursos económicos y de instrumentos técnicos para explotar sus propiedades de forma eficiente y rentable?. Si se toman en consideración estos interrogantes, se entienden mejor las polemicas suscitadas con referencia a si el SOC era consciente de los nuevos criterios de organización y de distribución de la producción que requiere la actual situación estructural de la sociedad agraria 0 , a si las altemativas propuestas por el mismo a los modelos de organización y de distribución de la producción vigentes en el agro son viables, a la vez que resulta más comprensible el interés manifestado, en diversas ocasiones, por parte de los componentes de dicho Sindicato, en mostrar que su organización reúne tales requisitos.

Desde otro punto de vista, la forma de conflictividad campesina canalizada a través del SOC refleja, también, las conductas y las actitudes típicas de un grupo de campesinos ante las transformaciones de su medjo agrario. Un medio que, analogamente al contexto rural tradicional en el que transcurrieron las tupicas revueltas campesinas andaluzas decimonónicas, se encuentra en proceso de crisis y de rearticulación por efecto de la modernización y de la consiguiente paulatina introducción en él de las relaciones capitalistas de producción y de mercado.

Los efectos de la modemización son ahora, obviamente, más intensos y de mayor envergadura que los de la pasada centuria; asimismo, en consecuencia, el medio rural en el que surge y se desarrolla el SOC se encuentra más integrado en la lógica económico-productiva global de la sociedad industrial. Por ello, aunque en dicha organización se manifiestan comportamientos y posiciones 
colectivas que revelan algunos vestigios de los rasgos peculiares de la tradicional conflictividad campesina decimonónica (que son enfatizados en este trabajo), el SOC presenta, además, unas características propias inherentes a la nueva situación del agro en la que ha surgido y se desenvuelve su praxis. Una siluación, en la que la modernización ya se ha afianzado casi por completo, tal y como se manifiesta en las conclusiones extraídas a partir del análisis de contenido de los textos del sindicato, las que pueden ser resumidas de la forma siguiente:

1) Sobre la mitificación del 'reparto'. En los años veinte de la presente centuria escribía, con referencia a este asunto, Díaz del Moral lo que a continuación se transcribe:

"Los propagandistas de la anarquía han rehuido siempre desarrollar las formulas en proposiciones concretas de inmediata ejecución; pero los campesinos andaluces, como casi todos los de España, les han encontrado un sentido preciso: el reparto, dividir las tierras en lotes iguales y sortearlos entre todos, como se hizo cuando la desamortización de bienes comunales, y como han hecho ellos en cuantas ocasiones han podido (...) Y no solo las masas, sino casi todos sus elementos directores, entienden que el problema de la tierra se reduce por ahora a la parcelación; casi ninguno confía en las aptitudes y la cultura de estos campesinos para la propiedad colectiva"(Díaz del Moral: 1979, 348).

En cierto modo, prosigue vigente en los documentos del SOC, relativos a los años estudiados, la mitificación del mero 'reparto' de la tierra característica de otros períodos de conflictividad campesina anteriores. En la generalidad de las organizaciones medianamente complejas es posible apreciar la existencia, más o menos arraigada según cada caso específico, de distintas corrientes de pensamiento y contradicciones ideologicas. Sin embargo, en el ideario de este sindicato, sobre todo por su carácter de movimiento social poco estructurado, tates corrientes y contradicciones suelen estar particularmente más destacadas, de tal forma que dicho ideario dista mucho de dejarse acotar bajo unos únicos presupuestos. De acuerdo con ello, junto a la continuación de la tradicional mitificación campesina del 'reparto', también existen en este Sindicato mues- 
tras de una concienciamas estructurada y acorde con una racional idad instrumental modema en consonancia con la lógica weberiana de la adecuación de los medios a los fines. Esto se manifiesta, por ejemplo, en uno de sus documentos alternativos con referencia a la reforma agraria, en el que ésta es entendida como un medio para lograr el fin consistente en una modificación de las actuales condiciones de propiedad y de mercado. Concretamente, en dicho documento, se establecen las bases a las que debe de ajustarse la reforma agraria en los têrminos siguientes:

- "Se trata de una reforma agraria que ha de basarse en dos pilares: A) una redistribución de la propiedad de la tierra que implique una utilización social de la misma; B) una reforma en profundidad de los canales de distribución, comercialización, transportes, y transformación de los productos agrarios y del sector de abastecimiento de materias primas para producir". Todo ello, porque el SOC considera que tener "la tierra no significa nada si el entomo, las condiciones de comercialización y abastecimiento, en una palabra, si las leyes del mercado (que son las que imponen los monopolios) no son profundamente alteradas" ("Progresar...jes..?...: 1979, 23).

2) Modernización rural, desempleo y crisis de la identidad colectiva campesina y jornalera. La modemización de la sociedad rural ha implicado una crisis en ella que, a su vez, se ha traducido en una desvalorizacion, por parte de los campesinos, de su actividad, la que acaba siendo considerada por ellos como un trabajo que se ven forzados a realizar ante la ausencia de otras altemativas. Como también la modemización conlleva la disminución de las oportunidades de trabajo en el medio agrario, otra reacción probable puede ser una pretendida reafirmación de la identidad jomalera, ante la amenaza de desaparición de esta ocupación a raíz del proceso modernizador. En consonancia con lo que se está afirmando, puede considerarse que el SOC ha constituido un intento de superar la pasividad pesimista y la desmovilización usual en muchos miembros del colectivo jomalero, los que son conscientes, por expresarlo con palabras del antropólogo Pablo Palenzuela, de que "su papel histórico comoclase fundamental de la sociedad andaluza ha pasado" $(1989,106)$. Ante esta situación, los componentes del SOC (continúo valiéndome de los términos que con referencia a la generalidad de los jomaleros andaluces emplea Pablo Palenzuela) "se

\section{ESTUDIOS}


resisten a perder su dignidad de trabajadores agricolas, les repugna tener que 'buscarse la vida' por otros medios que no sean los de la práctica de su oficio de jornaleros" $(1989,106)$.

Como dice un editorial de TYL, a "los jomaleros andaluces nos van retirando poco a poco del trabajo en el campo. Cada año hay menos peones y más paro. $Y$ cada mes que pasa se ven menos soluciones para nuestra vida (...). Queremos un puesto de trabajo. Y aquí en nuestra tierra es posible" ( $n^{2} 17$, abril de 1983). Se trata pues de una lucha por pervivir en su condición de jomaleros amenazada por la paulatina reducción de la mano de obra que conlleva la progresiva modemización y/o mecanización de los trabajos agrícolas.

Para la creación de empleo en el campo, se propone la implantación de una modalidad de reforma agraria que "cambie la estructura latifundista y privada de la propiedad de la tierra por el reparto colectivo y viable. Que la tierra, como bien público, pueda ser usada por cooperativas de trabajadores que aseguren mano de obra y estabilidad social" (Diamantino García Acosta en el "El Correo de Andalucía", 25-7-1988). Se trata de una reforma agraria que, en vez de planificar una estructura agrícola altamente tecnificada y acorde con las exigencias de la lógica mundial del mercado, elija, "otro tipo de agricultura con más empleo de mano de obra - cultivos de primor, hortalizas, árboles frutales, etc. - y considerable aumento del producto bruto. Este segundo modelo es difícimente conciliable con la gran propiedad individual, sobre todo, en regadío. Y, sin embargo, es vital para ofrecer trabajo a los jomaleros" (TYL: ${ }^{\circ}$ 7, abril de 1982, pág. 2). Todo ello, como altemativa a una situación que es percibida por los miembros del SOC como producto de un conjunto de medidas socio-económicas y políticas tendentes a suprimir a los jomaleros del panorama laboral andaluz. Así, Diamantino García Acosta escribía lo siguiente:

"En los planes del actual sistema capitalista, los jornaleros no somos necesarios. Unicamente nos emplean en cuatro temporadas puntuales, y cada vez más cortas, para las que todavía no han encontrado máquinas que las labren o cosechen. Pero la consigna del sistema, es decir, de los grandes terratenientes, de las multinacionales y de la política agraria del gobierno, es no dar trabajo en el campo. Máquinas en lugar de hombres (...). El subsidio de desempleo va en esta línea de destruimos en cuanto trabajadores. Acostumbra a la gente a malvivir sin trabajar, pues te dan una pequeña 
paga durante nueve meses al año a cambio de presentar unas peonadas que el patrón firma en bastantes casos fraudulentamente. (...). Nada de fácil es la situación que está viviendo la gente del campo. No podemos esconder la cabeza debajo del ala, ni confomarnos con la 'droga' del desempleo o con pretender la jubilacion anticipada. Hay salidas más dignas que entre todos debemos de buscar con esfuerzo, con sacrificio y con imaginacion. La organización a la que pertenezco desde hace años está entregada a este empeño y por eso reclamamos con insistencia tierra, trabajo y dignidad para los jomaleros andaluces" (El Correo de Andalucía, 23-11-1987).

El texto que se acaba de transcribir refleja muy bien la conciencia agonica de los jornaleros, ante su irremisible desplazamiento del ámbito productivo agrario, como consecuencia de la inevitable y progresiva inserción del mundo rural en la dinámica global de la economfa de mercado y de la sociedad industrial moderna, lo que conlleva una creciente reducción de las necesidades de mano de obra agrícola. Aparte de ello, en tal tex to se refleja también cómo la demanda de tierra, prototípica de las luchas por el 'reparto' de otros períodos históricos (sobre todo, en el siglo $\mathrm{XIX}$ ), se conjuga ahora con la reivindicación de las condiciones socio-economicas que les pernitan a los jomaleros la recuperacion de su dignidad y el consiguiente mantenimiento de su situación laboral de siempre. Situación esta, a la que parecen aferrarse con especial fuerza, ante la amenaza de desaparición de la actividad en tomo a la que, durante siglos, se ha estructurado su identidad colectiva. Ante tal situación los jomaleros se empeñan en seguir viviendo de la tierra, lo que, a fin de cuentas, significa continuar persistiendo como tales. Como dice un mensaje publicitario, en el que se invita a los lectores a subscribirse a TYL, los "jomaleros no somos aves para vivir del aire, no somos peces para vivir del mar, somos hombres para vivir de la tierra" (TYL: $n^{0}$ 15, enero de 1983, pág. 8).

La persistente situación de desempleo en la que se encuentran los jornaleros incide en la manera que éstos tienen de explicar los factores causantes de su situación social. Situación que ha estado caracterizada por la paulatina expulsión del mercado laboral y por la intervención de la Administración Pública (por ejemplo, subsidiando a los, cada vez mís numerosos, parados agrarios) que:

“...se ha venido instrumentando en la úllima década, con cl deterioro que 
ya conocemos y con el consiguiente predominio de los componentes depresivos (...)la actitud jomalera actual es el producto de un proceso de desarraigo y de desvinculación de la tierra, al término de la cual el colectivo jomalero se enfrenta a una situación contradictoria y rodeada de incertidumbre. Pues, habiendo perdido su tradicional vínculo con la agricultura, tampoco dispone de altemativa alguna adonde dirigirse, contradicción insuperable, por el momento, que se expresa en su radical crisis de identidad" (J. J. González: 1990, 255-256).

La pérdida de su tradicional vínculo con la agricultura y el verse impelidos a vivir del subsidio repercute en un replanteamiento de los factores y/o de los causantes de la situación de los jomaleros por parte de éstos. Dicho de otro modo más preciso, el hecho de vivir persistentemente del subsidio de desempleo contribuye a que los jomaleros tiendan a dejar de proyectar sobre el referente del "patrón" la responsabilidad de los males que aquejan al mundo rural en el. que se desenvuelven. Como señala Diamantino García Acosta, al "ser progresivamente expulsado de la produccion, el obrero agrícola ha perdido toda referencia al patrón como antes se le conocía. El patrón hoy sólo se refiere al subsidio, como el que firma las peonadas para tener derecho a la pequeña pensión" (El Correo de Andalucía: 15-5-1990). Todo ello, obviamente, ha supuesto cambios profundos en la identidad colectiva y en la percepción que de su propia situación tienen los jomaleros, los cuales, con frecuencia, han acabado por sumirse en la desorientación y en el pesimismo, dada su improbable supervivencia futura como colectivo presente en el agro andaluz.

3) Reacción campesina ante la implantación de las relaciones capitalistas de mercado. Tradicionalmente los campesinos han concebido la tierra como un valor de uso. La implantación generalizada de las relaciones capitalistas de mercado, el establecimiento de una economía de carácter monetario y de una nueva tecnología, hacen que la explotación agraria de naturaleza familiar o doméstica acabe convirtiéndose, gradualmente, en una empresa de tipo capitalista. Asimismo, la expansion de las relaciones de mercado conlleva, habitualmente, un proceso de proletarización en la agricultura que transcurre paralelo al desarrollo de explotaciones agrícolas o ganaderas de carácter agroindustrial y/o comercial. Como hemos visto, el proceso de proletarización de la mano de 
obra agrícola alcanzó en Andalucía occidental (área de máxima implantación del SOC) su punto culminante a fines de la pasada centuria. El problema que se plantea, actualmente, es el de la necesidad de proceder a una paulatina reducción de la fuerza de trabajo dedicada a la agricultura.

Entre otros aspectos, el SOC puede ser concebido como una organización sindical reivindicativa tendente a resistirse a los efectos de la modernización y a proponer unas alternativas que, dejando de lado la cuestión de su viabilidad económica (todo dependerá, en definitiva, del criterio socio-económico con que sea determinada dicha viabilidad), constituyen una reacción de un grupo de jofnaleros frente a la paulatina introducción en su mundo de las relaciones capitalistas de producción y de mercado, tal y como ellos las perciben y sufren sus consecuencias en su vida y economía doméstica coticianas.

4) En torno al tradicional apoliticismo campesino y su posible incidencia en el SOC. Se pueden observar notables vestigios de la característica actitud de repudio de los anarquistas decimonónicos ante la política entre los componentes del SOC. Así, una de las modalidades de organización y de articulación social, propugnadas por este movimiento campesino, es la democracia asamblearia. Juan Manuel Sánchez Gordillo, tal vez el más conocido de los líderes del SOC, escribía con motivo de unas elecciones municipales lo siguiente:

"De ahí que digamos que el Alcalde tenga que ser todo el pueblo y no una persona. Y no debemos permitir que nadie guarde, una vez celebradas las elecciones municipales, el poder del Ayuntamiento en el cajón de su despacho, ni tan siquiera en la elegante sala donde se realizan los plenos (...) , sino que, al contrario, sea la asamblea del pueblo quien ostente la últtma palabra a la hora de decidir los asuntos importantes del municipio (TYL, $\mathrm{n}^{\mathrm{o}} 18$, mayo de 1983, pág. 1).

En otra parte, el propio Sánchez Gordillo se expresaba, con respecto a esta cuestion, en los términos que a continuación se transcriben:

"Creemos que el poder no puede estar acumulado en pocas manos, sino repartido entre los vecinos; por eso creemos que los concejales deben ser elegibles y revocables en todo momento por la asamblea del pueblo, que 
es la que debe tener el poder de decisión" (TYL, $\mathrm{n}^{\mathrm{0}} 15$, enero de 1993 , pág. 6)".

Estas ideas han sido, prácticamente, materializadas en Marinaleda durante los afros que Sánchez Gordillo ha venido desempeñando la alcaldía de este pequeño pueblo sevillano. De todos modos, y sin dejar de encomiar la honradez de tales propositos y de reconocer las justificadas motivaciones (sobre todo, la inercia e incapacidad de la maquinaria burocrático-política oficial para llegar, habitualmente, a los problemas e inquietudes que afectan a la cotidianeidad de mucha gente) que han llevado a Gordillo y a sus seguidores a reafirmarse en y/ o a adoptar dichas ideas, no podemos evitar cuestionamos acerca del alcance global que podría tener la modalidad de democracia asamblearia cuando se sale del marco local de un pueblo como Marinaleda, relativamente homogéneo en lo social por tratarse una población en su mayoría jomalera, y se entra en el de las complejas estructuras burocrático-políticas, que requieren, tanto para su organización como para su reproduccion y pervivencia en el tiempo, las altamente estatalizadas sociedades avanzadas actuales.

En tales sociedades, la experiencia histórica y los conocimientos de teoría económica, política y sociológica existentes en ellas incitan a un planteamiento global de los problemas especificos que en ellas se suscitan, a la vez que parecen corroborar la inviabilidad de realizacion de cualquier proyecto (a la usanza rouseauniana) de democracia asamblearia directa, al menos a nivel global, ya que esta modalidad democrática sólo suete funcionar cuando se desarrolla en el seno de grupos pequeños y bastante homogéneos en su composición, cuyos planteamientos ideológico-cuturales y expectativas presentan acusadas similitudes. Lo que prevalece en las altamente burocratizadas y complejas sociedades contemporáneas es la conciencia generalizada de que la necesidad de encomendamos (hipotecarnos (?)) a personas e instituciones mediadoras que nos representen se nos muestra, en la actualidad, como una precondición insoslayable para el funcionamiento eficaz de cualquier democracia moderna (Entrena: 1989, 615) 7 . Pero, de lo que se acaba de decir no ha de desprenderse

(7) De ahí, la necesidad de propiciar la existencia de cauces institucionales para el control colectivo del poder en las sociedades avanzadas actuales, como única forma de hacer posible que éstas sean realmente democráticas. 
la idea de que experiencias como la de Marinaleda resultan por completo infructuosas, pues, a pesar de las limitaciones de la aspiracion rousseanoniana, continúa teniendo vigencia el ideal en ella paradigmatizado a través del concepto de "voluntad general"; especialmente, en lo que se refiere a su dimensión utópica y al efecto dinamizador sobre el cambio social que se puede derivar de su potencialidad critica y subversiva sobre el status quo establecido.

En el caso que nos ocupa, el ideal asambleario orientador de la praxis de estos miembros del SOC podría ser tipificado como una tentativa de realización de la "voluntad general", a través de la materialización de un modelo de orden social en el que es posible el pleno desarrollo de la justicia, la igualdad y la libertad humanas sin necesidad de ninguna mediación que las detemine o limite. Se trata de algo muy parecido a lo que ha constituido el horizonte utopico de referencia del anarquismo campesino-tradicional, tan magistralmente descrito por Díaz del Moral (1979). Y, si se tiene en cuenta el paralelismo que puede establecerse entre los prístinos ideales de comunidad, justicia y equidad del cristianismo y los del anarquismo, resulta completamente logica la opción de determinados sacerdotes de afiliarse $y / 0$ comprometerse en favor de la causa defendida por el SOC. Este es el caso de ciertos líderes significados del sindicato como el cura párroco de la localidad sevillana de Los Corrales, Diamantino García Acosta, o de Esteban Tabares, que también ha sido sacerdote.

5) Referentes legitimadores de la movilización campesina en los miembros del SOC. El "socialismo real" y el ecologismo han constituido dos importantes referentes legitimadores (es decir, explicativos y/o justificadores) de las movilizaciones y aspiraciones programáticas del SOC. Ello no implica que aquellos componentes y simpatizantes de este Sindicato identificados con tales referentes hayan manifestado siempre tener una clara percepción de la complejidad de las implicaciones político-burocráticas y/u organizativas que conlleva la implantación y el mantenimiento de cualquiera de los llamados regimenes "socialistas". De acuerdo con su ya mencionado modelo de referencia asambleario, Juan Manuel Sánchez Gordillo ha escrito lo siguiente:

"Si queremos la libertad, la desaparición de las clases, el reparto de la tierra, el socialismo y una sociedad verdaderamente justa, humana $e$ igualitaria, no podemos faarnos más que de nosotros mismos y huir como 
el diablo cuando la burguesía nos regale trocitos siempre envenenados de poder" (TYL, nº 4-5, enero de 1982, pág. 5).

Por lo que se refiere al ecologismo, aunque siempre ha estado presente en el Sindicato la ideología inherente al mismo, se ha ido reafirm ando, entre los miembros del SOC, una corriente que lo enfatiza de manera especial, precisamente a medida que éstos han ido experimentando el incremento gradual de su impotencia para llevar a cabo una acción efectiva, sobre todo, en lo relativo a lograr sus aspiraciones de 'reparto' de la tierra a través de la movilización. Como ejemplo de ello, en julio de 1989 aparece un articulo firmado por Paco Casero (destacado representante de dicha corriente ecologista) en un número de TYL, en el que se relata cómo el SOC actúa en conjunción con otras organizaciones ecologistas por la recuperación de las cañadas (antiguas vías de tránsito de ganado) como el espacio público que antaño fueron.

En cualquier caso, el socialismo, tal y como se ha dicho que lo conciben estos campesinos, y el ecologismo resultan conjugables, simultáneamente, en la mentalidad rural de los miembros del SOC; pues, al fin y al cabo, para estos jomaleros, el respeto a la naturaleza implica también el respeto al entomo en el que viven como colectivo. Desde estos planteamientos, se considera que, difícilmente, tendrá en cuenta las exigencias vitales de la colectividad una forma de explotación de la tierra que, como la del interés privado de la economía capitalista de mercado ajena a los requerimientos específicos de los campesinos de una determinada zona, tiende a anteponer el bien particular y/o meramente económico al social.

Análogamente a como sucediera en las revueltas campesinas de la España decimonónica y en las de otros países del mundo a lo largo del siglo $\mathrm{XX}^{8}$, la del SOC se trata de una aspiración que, globalmente, podría ser tipificada como tendente a lograr la autonomia de los campesinos y la posibilidad de que éstos autogestionen su entomo y sus propios asuntos. En realidad, puede afirmarse que los jornaleros del período estudiado de este Sindicato se identificaban con el socialismo porque veían en él algo así como un medio de

(8) Uno de más renombrados estudios, con referencia a las revueltas campesinas mundiales en el sig lo XX, es el de Eric R. WOLF (1979). Obra en la que se analizan los casos de México, Rusia, China, Vietnam, Argelia y Cuba. 
materializar su ideal de democracia asamblearia y, consiguientemente, de realizar la ancestral aspiración comunitaria que suele estar más o menos presente en la generalidad de la conciencia colectiva de bastantes sociedades rurales. El socialismo, desde estos presupuestos, representa para los campesinos tanto como la posibilidad de concreción de una sociedad rural, en la que, en vez de la primacía del interés individual particular, característica del paradigma de la sociedad de mercado que se impone cada vez más a fondo con la modemización, lo colectivo y/o lo grupal se anteponen a lo individual, las necesidades sociales (una de las más fundamentales de ellas es la de trabajar, la de tener un lugar reconocido en el ámbito socio-productivo) se sitúan por encima de las exigencias de la mera rentabilidad económica. Así pues, se trata de una sociedad rural concebida por y para unos hombres, cuya vision de las cosas, aspiraciones y necesidades están, sobre todo, en consonancia con lo que ellos entienden que se ha requerido tradicionalmente en su mundo campesino.

\section{A modo de conclusión}

En primer lugar, hay que precisar que el carácter generalista y un tanto "moralizante" de esta conclusión se debe a tres razones básicas. De una parte, como ya se ha dicho antes, a la necesidad de adoptar una perspectiva global para entender la problemática socio-económica de cualquier sociedad relativamente compleja, como es el caso de la andaluza actual en torno a la que ha surgido el SOC; de otro lado, a ta exigencia de reflexionar sobre las posibles soluciones a ello teniendo en cuenta la dinámica conjunta de la economía y de la sociedad de hoy. Por último, el tono "sermoneador" de este remate de mi trabajo se justifica en la conciencia de que, como ya se manifestara a partir de los escritos de Max Weber, toda tentativa de neutralidad valorativa resulta en última instancia imposible de conseguir. Tras cualquier actuación humana subyace siempre (independientemente de que se manifieste o no y de que se sea o no consciente de ello) una opción de valor. Es mejor intentar explicitar la altemativa moral que subyace a dicha forma actuación", pues, de no obrar así, se corre el riesgo de ser partícipe inconsciente de la reproducción de criterios normativo-morales legitimadores del sistema establecido. Riesgo que hay que

(9) El ejercicio de la actividad cientifica es encuadrable dentro de esta forna de actuación. 
tratar de evitar a toda costa, entre otras razones, porque la tarea de los sociólogos, "en tanto que estudiosos de la sociedad, no es, necesariamente, contribuir a legitimar o a subvertir la misma, sino, sobre todo, conocer lo mejor que podamos sus mecanismos estructurales de organización, funcionamiento y evolución" (Entrena: 1992 (a), 91 ).

Los jornaleros del SOC rechazan la modernización porque ésta conlleva la paulatina desarticulación de su mundo y una creciente pérdida de empleo ${ }^{10}$. Hay que precisar que lo que, básicamente, se repudia son los efectos descontrolados de la modernización, la creciente desaparición de puestos de trabajo agrarios que la misma conlleva sin que se ofrezcan altemativas de empleo que los reemplacen.

"Claro que sería ilusorio pensar que todo el paro agrícola andaluz puede ser reabsorbido de nuevo trabajando en el campo. No se le puede pedir a la agricultura que solucione el paro de miles de jomaleros y campesinos. Hay que desarrollar otros sectores de la vida rural, empleando en ellos a quienes ya no podrán trabajar nunca más en el campo"(Esteban Tabares: TYL: julio de 1989, pag. 2).

En realidad, la creciente disminución de la población activa agrícola se inserta, también, en la lógica excluyente, en la que, en la actualidad, se encuentran las sociedades industriales avanzadas. Dinámica excluyente que ha implicado una exigencia de ir apartando, de manera gradual, recursos materiales y humanos de la producción, motivada, sobre todo, por el incremento de la eficacia productiva derivada del desarrollo tecnologico, que ha dado lugar a una crisis de superproducción sin precedentes en tales sociedades, junto a la que, paradojicamente, existen las graves dificultades derivadas de la escasez crónica y de la miseria extrema de esos dos tercios del planeta denominados por muchos como el tercer mundo. En este contexto, las soluciones y/o medidas de desarrollo a aplicar al agro no pueden desligarse de las respuestas que precisa

(10) "Los hombres trabajando....las máquinas paradas" es el texto del pie de unas folografias aparecidas en TYL de julio-agosto de 1982, pág. 4. Todo ello, seguido de un pasaje en el que se explican los logros de la lucha jomalera en su demanda de que la recolección de la remolacha sea efectuada manualmente, a fin de aumentar el número de puestos de trabajo. 
La sociedad en su conjunto, cuya economía es cada vez mós interdependiente a nivel mundial. En definitiva, en una sifuación caracterizada por la mundialización económico-productiva y de los problemas sociales, las soluciones tienen, forzosamente, que ser globales. En concreto, en el caso de nuestro entomo geopolítico, la consecución de un marco europeo globalmente solidario, tanto con sus excluidos intemos como con las poblaciones sumidas en la pobreza de las areas del mundo menos desarrolladas es una cuestion que, más allá de sus imperativos éticos, se plantea como un prerrequisito básico para garantizar la estabilidad y la paz.

Soluciones globales de solidaridad que, más allá de la inevitable mejora de la eficiencia y de la calidad productiva en una economía cada vez más competitiva, plantean retos como la necesidad de ahondar en el presente debate acerca de una redistribución del trabajo disponible y del consiguiente replanteamiento de la actual distribución del tiempo de actividad y de ocio, de la reafimación e incluso aumento de los niveles de protección colectiva inherentes a la sociedad de bienestar hoy seriamente amenazada, y, en definitiva, del replanteamiento global de todo el modelo económico-productivo vigente. Todo ello difícilmente se conseguirá sin una adecuada planificación de la intervención publica, ya que es dudoso, como parecen presuponer las orientaciones neoliberales actualmente imperantes, que el funcionamiento automático de las fuerzas del mercado y la mera iniciativa privada acaben por resolver por sí solas los graves problemas económico-sociales actualmente existentes.

Por otra parte, conviene hacer notar que el discurso utopico-radical, que con tanta fuerza se manifestó en el anarquismo decimonónico, y del que existen vestigios entre los líderes del SOC durante el periodo analizado, era mas viable en una sociedad fragmentada y relativamente localista como la que entonces existía. Una sociedad tradicional, en la que era factible que deteminados colectivos campesinos, que veían su situación anenazada por las medidas modernizadoras del Estado, tuvieran posibilidades de replegarse en los paradigmas simbolico-conceptuales de su propio mundo (usualmente ajenos, como es sabido, a los presupuestos político-estatales urbanos), así como de organizarse y de construir su utopía y/o altemativa contra el sistema vigente de acuerdo con ellos. Entre otros motivos, ello podía suceder porque, todavía por entonces, los campesinos no habían sido integrados o absorbidos plenamente por el Estado. 
314 EL SOC UN CASO DE REACCION CAMPESINA ANTE LA MODERNIZACION RURAL

En la realidad de la "aldea electronica global", de un mundo cada vez más integrado en la logica cultural urbano-estatal y del mercado a nivel planetario, no deja de resultar un tanto quimérico plantearse vivir al margen del sistema. En este contexto tiende a generalizarse el reformismo. También existirán condiciones más adecuadas para la generalización de dicho reformismo en tanto que, frente a la crisis que evidentemente implica el proceso de modemización, para la vida, la situación económica, y las posibilidades de empleo de la sociedad rural, puedan ir afianzándose, poco a poco, alternativas de recualificación profesional y de desarrollo rural que propicien una paulatina reubicación social y laboral de estos trabajadores agrícolas y/o jornaleros. Afianzamiento del reformismo que hay que precisar que no implica, necesariamente, conformismo con el status quo y/o resignación a éste, sino que lo que ello refleja es la consciencia de que no hay salida viable al margen del sistema. De ningún modo se trata, pues, de renunciar a reconducir el sistema, a procurar desarrollar desde dentro del mismo los ideales de justicia y de equidad. Por contra, los esfuerzos han de centrarse en propiciar que la democracia sea cada vez más completa, lo que, a su vez, supone un aumento progresivo del nivel de control colectivo sobre las decisiones que afectan tanto al funcionamiento como al cambio del sistema socio-económico y político. En cualquier caso, esto nos incita a reflexionar en tomo a cómo se perfeccionan las formulas de participación democrática ya existentes (a la vez que se articulan otras nuevas en este sentido) que permiten irmás allá del mero hecho de depositar un voto cada cierto número de años en una urna.

Las organizaciones sindicales agrarias, en lo que concieme al mundo rural, pueden y deben desempenar un papel crucial en la articulación y canalización de la acción económico-social-política. Ello, de cara a avanzaren la materialización del control democrático y/o colectivo de la marcha y del cambio de la sociedad rural, que no puede ser desvinculado del de la sociedad en su conjunto. 


\section{BIBLIOGRAFIA}

ÁLVAREZ JUNCO, JOSE(1976), LA IDEOLOGIA POLITICA DEL ANARQUISMO ESPAÑOL(18681910), Siglo XXI EDTTORES, MADRID.

BARRAGÁN, A.; GONZÁLEZ, M; Y, SEVILLA,E. (1985), "REVULITAS CAMPESINAS EN ANDALUClA", CuADERNOS DE HISTORIA 16, № 294, MADRID.

CARRIÓN, P. (1932), LOS LATIFUNDIOS EN ESPANA. SUIMPORTANCIA, ORIGEN, CONSECUENCIAS, SOlUCIÓN. ED. ARIEL, Madrod (Facsimiz, 1972).

Correo de ANDAlucta, El, diversos articulos de miembros destacados del S.O.C., QUE APARECEN EN ESTE PERIÓDICO.

Cuaḱto Congraso dei SOC. Cambia la Realidad del Sindicato (1987), Sevilla, dias $4,5 \times 6$ DE SEPTIEMBRE.

DIAZ DEL MORAL, J. (1979), HISTORIA DE LAS AGITACIONES CAMPESINAS ANDALUZAS, ALIANZa EdITORIAl, Madrid.

ENTRENA DURÁN, Francisco (1989), "SObRE LA CRISIS dE la modernidad", RELIIÓN Y CULTURA, $\mathrm{N}^{2} 171$

ENTRENA DURÁN, Francisco (1992(A), LA NATURaleza Y EL DESARRollo dE LA Soctologia, Ed. Comares, Granada.

ENTRENA DURÁN, Francisco (1992(B), "CAMBIOS EN LA CONCEPCIÓN Y EN LA organizactón del espacio rural", Revista de Estudios Regionales, № 34, Malaga,

GONZÁLEZ, JuAN Jesús (ENERO-MARZO 1989), "El Discurso JorNALERo: DESARTICU-

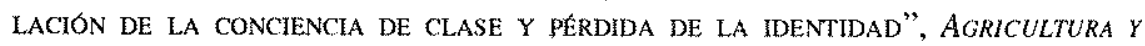
SOCIEDAD, N 50.

GONZÁlEZ, Juan Jesús (enero-marzo 1990), "El. desempleo rural en ANDalucta Y EXTREMADURA", AGRICULTURA Y SOCIEDAD, N $N^{9} 54$.

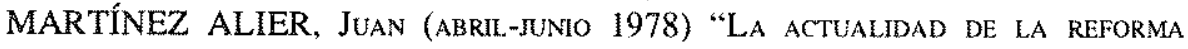
AGRARIA", AGRICULTURA Y SOCIEDAD, No 7.

MOYANO ESTRADA, EDUARDO (OCTUBRE-DICIEMBRE 1984) "IIIEOLOGIAS Y SINDICALISMO AGRARIO EN LA TRANSICIÓN DEMOCRÁtTCA ESPAÑOLA", AGRICULTURA Y SOCIEDAD, $N^{0} 31$,

MOORE, BaRRENGTON JR. (1991), LOS ORIGENES SOCIALES DE LA DICTADURA Y DE LA DEMOCRACIA. EL SENOR Y EL CAMPESINO EN LA FORMACIÓN DEL MUNDO MODERNO, EDICIONES Peninsula, Barcelona.

MORALES RUIZ, RAFAEL: Y, BERNAL, ANTONIO Miguel (1993) "AproXIMACIÓN A LA HISTORIA DE LAS CCOO. DE ANDALUCfa (1962-1978)", EN DAVId RUiz (DrR.) Historia de las Comisiones Obreras (1958-1988), Siglo XXI editores, Madrid.

PALENZUELA CHAMORRO, Pablo (ENERo-Marzo 1989), "Estrategias eConómiCAS DOMESTICAS DE LOS JORNALEROS ANDALUCES: SALARIO, SUBSIDIO $Y$ ECONOMIA SUMERGIDA", AGRICULTURA Y SOCIEDAD, № 50.

\section{ESTUDIOS}


PÉREZ YRUELA, M. (1985), "LA Reforma agraria en España", Cuadernos de HISTORIA 16, $\mathrm{N}^{2}$ 239, MADRID.

"Progresar...jes no comer?. Alternattva del S.O.C. A la actual sttuación del CAMPO ANDALUZ" (1979).

SÁNCHEZ JIMÉNEZ, JOSÉ (1985), DEL CAMPO A LA CIUDAD. MODOS DE VIDA RURALY $Y$ URBANA, Ed. Salvat EDTTORES S.A., Barcelona.

(TYL) "Tierra y Libertad", periódico del. S.O.C. Del Que se consultan varios NÚMEROS QUE APARECEN CITADOS EN EL TEXTO.

WOLF, ERic R. (1979), Las luchas campesinas del Siglo XX, Siglo XXI edtTores, México. 